\title{
Hepatocellular carcinoma in a green iguana - a case study
}

\author{
Zdeněk Knotek ${ }^{1,2}$, Gerry M. Dorrestein ${ }^{1,3}$, Anna Hrdá1 ${ }^{1}$, Aleš Tomek ${ }^{4}$, Pavel Proks ${ }^{5}$, Zora \\ Knotková ${ }^{1}$, Vladimír Jekl ${ }^{1}$, William Lewis ${ }^{6}$ \\ ${ }^{1}$ Avian and Exotic Animal Clinic, Faculty of Veterinary Medicine, University of Veterinary \\ and Pharmaceutical Sciences, Brno, Czech Republic \\ ${ }^{2}$ Clinic for Avian, Reptile and Fish Medicine, University of Veterinary Medicine, Vienna, Austria \\ ${ }^{3}$ Diagnostic Laboratory NOIVBD, Veldhoven, The Netherlands \\ ${ }^{4}$ Clinic Jaggy, Brno, Czech Republic \\ ${ }^{5}$ Small Animal Clinic, Faculty of Veterinary Medicine, University of Veterinary and Pharmaceutical Sciences, \\ Brno, Czech Republic \\ ${ }^{6}$ Wylie Veterinary Centre, Upminster, United Kingdom \\ Received September 22, 2010 \\ Accepted April 6, 2011
}

\begin{abstract}
A $3.10 \mathrm{~kg}$, six-year old male green iguana (Iguana iguana) suffered several weeks of decreased activity, loss of body weight, anorexia and change of skin colour. Physical examination revealed a cachectic depressed lizard, with marked pale mucous membranes. The complete blood count revealed a leukocytosis $\left(46.5 \times 10^{9} / 1\right)$, elevated heterophils $\left(23.25 \times 10^{9} / 1\right)$ and azurophils $\left(23.25 \times 10^{9} / 1\right)$, decreased haemoglobin concentration $(29.00 \mathrm{~g} / 1)$, low haematocrit $(0.16 \mathrm{l} / \mathrm{l})$ and erythropenia $\left(0.35 \times 10^{12} / 1\right)$. Abnormalities of the plasma chemistry panel included increased activity of aspartate aminotransferase $(6.05 \mu \mathrm{kat} / \mathrm{l})$ and creatinephosphokinase $(217.91 \mu \mathrm{kat} / \mathrm{l})$, increased concentrations of uric acid $(321.58 \mu \mathrm{mol} / \mathrm{l})$, phosphorus $(4.04 \mathrm{mmol} / \mathrm{l})$ and bile acids $(120.21 \mu \mathrm{mol} / \mathrm{l})$, as well as a decreased concentration of glucose $(3.72 \mathrm{mmol} / \mathrm{l})$, cholesterol $(0.637$ $\mathrm{mmol} / \mathrm{l})$ and triglycerides $(0.09 \mathrm{mmol} / \mathrm{l})$. A lateral radiograph revealed soft-tissue opacity present in the region of the liver. Magnetic resonance imaging showed a markedly enlarged left liver lobe distended caudally and displacing the other abdominal organs. The signal intensity of the liver parenchyma was slightly hyperintense, the ventro-medial part of the left lobe showed a hypointense signal. Endoscopic examination of the coelomic cavity revealed a greatly enlarged pale liver and the presence of a straw-coloured modified transudate. Based on histopathological examination of the liver hepatocellular carcinoma was diagnosed. Despite supportive treatment the patient died on the sixth day of hospitalisation.
\end{abstract}

Reptiles, liver disease, plasma chemistry, bile acids, MRI

Different types of liver diseases are common in captive reptiles. Monitoring of liver function in reptiles is not easy and cannot be based purely on measuring the activities of plasma enzymes like alkaline phosphatase (ALP), alanine aminotransferase (ALT), and aspartate aminotransferase (AST), because the large reserve capacity of the reptilian liver function makes such evaluation incorrect. Using magnetic resonance imaging (MRI) to assess focal lesions of the spleen and liver has been well documented in dogs (Clifford et al. 2004) and the diffuse and focal pathological processes in different organs and soft tissues are documented with MRI imagines in human and veterinary medicine (Gumpenberger and Henniger 2001; Oliva and Saini 2004; Bialecki and Bisceglie 2005; Aguirre et al. 2006; Hecht et al. 2006; Silverman 2006; Elsayes et al. 2007; Knotek et al. 2007; Szklaruk and Bhosale 2007).

\section{Materials and Methods}

A $3.10 \mathrm{~kg}$, six-year old male green iguana (Iguana iguana) suffered several weeks of decreased activity, continuing loss of body weight, anorexia and change of skin colour. The iguana was kept as a single pet indoors in a terrarium $(1.45 \times 0.9 \times 0.6 \mathrm{~m})$ with temperature ranges between 24 and $35^{\circ} \mathrm{C}$, air humidity between 60 and $80 \%$ and a specific light regime (12h/12 h of light and dark, $100 \mathrm{~W}$ bulb + UV lamp Repti-Glo 5.0, Hagen). The diet

Address for correspondence:

Prof. MVDr. Zdeněk Knotek, CSc.

Avian and Exotic Animal Clinic, Faculty of Veterinary Medicine

University of Veterinary and Pharmaceutical Sciences

Brno, Czech Republic
Phone: +420604205305

Fax: + 42541562381

E-mail: knotekz@vfu.cz

http://www.vfu.cz/acta-vet/actavet.htm 
consisted of dandelion leaves, carrots, lettuce, apples, Chinese cabbage and pelleted commercial chow (Iguana Adult, ExoTerra, Germany). The owner reported a profound decrease in activity and appetite starting two weeks before the presentation on clinic. Physical examination revealed a cachectic quiet lizard with depressed attitude, yellow skin and marked pale mucous membranes (Plate I, Fig 1). Abdominal palpation revealed minimal content in the gastrointestinal tract. Gentle palpation of the terminal part of the colon through the cloaca did not reveal any evidence of renomegaly. During physical examination of the patient and gentle cloacal washing the iguana produced faeces and a large volume of dense urine with a green colour.

A heparinised blood sample $(2 \mathrm{ml})$ was collected from the ventral coccygeal vein (vena coccygea ventralis), using manual restraint. The haematocrit (PCV) was measured by the microhaematocrit method, haemoglobin $(\mathrm{Hb})$ was determined by the cyanmethaemoglobin method, and total red and white blood cell counts performed according to the Natt and Herrick method (Knotek et al. 2002; Pejřilová et al. 2004). Blood smears were airdried and stained using May-Grünwald and Giemsa-Romanowski stains. Two hundred leukocytes were counted for each smear and classified as heterophils, eosinophils, basophils, lymphocytes, azurophils or monocytes (Pejřilová et al. 2004).

The blood sample was placed in a tube containing heparin (50 i.u./ml Heparin Léčiva inj., Prague, Czech Republic) and was centrifuged. Plasma biochemical assays were performed within $2 \mathrm{~h}$ after collection by the use of automated analyzers (Knotková et al. 2005). The activity of ALP, ALT, AST and creatinephosphokinase (CPK), as well as concentration of total protein, glucose, uric acid, cholesterol, triglycerides (TAG) and phosphorus was determined with a CobasMira analyzer (Roche, Switzerland); plasma concentrations of calcium were determined using a AA Series Spectrometer (Thermo Electron Corporation, UK). Bile acid concentration was performed using a single enzymatic colorimetric assay (Bile Acids, Randox Laboratories GmbH Krefeld, Germany) with the use of spectrophotometer (PCP 6121 Eppendorf, Germany).

The iguana was sedated with tiletamine-zolazepam at a dose of $25 \mathrm{mg} / \mathrm{kg}$ given by the subcutaneous route (Zoletil $500 \mathrm{mg}$, Virbac, France). Lateral and dorsoventral full-body radiographs were obtained using a Proteus XR (GE Medical Systems, USA) and digital automatic system FCR Capsula XL (Fuji, Japan). Magnetic resonance imaging (MRI) examination was performed with a 0.2 Tesla permanent magnet MRI unit (Vet-MR 0.2 T, Esaote, Italy). The iguana was positioned in sternal recumbence (Plate I, Fig. 2). The signal intensity on the MRI images was estimated with the signal intensity of the dorsal paraspinal musculature. Endoscopic examination of the coelomic cavity was performed under isoflurane anaesthesia using a rigid endoscope, an examination sheath and a xenon light source (Hopkins Documentation Forward-Oblique Telescope 64018 BS, ø 2.7 mm, 18 cm; 67065 CC; Xenon Nova 20131520, Karl Storz Tuttlingen, Germany). The image was scanned by an endoscopic camera (Endovision Telekam SL 20212001, Karl Storz, Tuttlingen, Germany) connected to a monitor (Sony) and a VCR (Video Recorder SVHS ET, JVC). During the endoscopic evaluation of the pleuroperitoneal cavity samples of effusion fluid were collected for cytological and chemical examination.

During hospitalisation at the clinic the iguana was treated with enrofloxacin at a dose of $10 \mathrm{mg} / \mathrm{kg}$ every $24 \mathrm{~h}$ (Enroxil 5\% inj. ad us. vet., Krka, Slovenia), vitamin B (B-neuron inj. ad us. vet., Chassot, Switzerland), aminoacids (Heparemin inj. ad us. vet., Biotika, Slovakia) and fluids (20-30 ml/kg, Duphalyte inj. ad us. vet., Fort Dodge Animal Health, USA diluted 1:5 with $\mathrm{NaCl} 0.9 \%$ Braun) given by the subcutaneous route. Despite the treatment, the condition of the iguana deteriorated and the iguana died on the sixth day of hospitalisation. Necropsy was performed immediately. Samples of liver, heart, lungs, kidneys, oesophagus, pancreas, spleen and stomach were fixed in $10 \%$ buffered formalin. Tissue sections were submitted for histological examination to the Dutch Research Institute for Birds and Exotic Species (NOIVBD, Veldhoven, The Netherlands).

\section{Results}

The results of the blood profile are presented in Table 1. The complete blood count revealed a leukocytosis, elevated heterophils and azurophils, decreased haemoglobin concentration, low haematocrit and erythropenia. Abnormalities of the plasma chemistry panel included increased activities of AST, CPK, increased concentrations of uric acid and phosphorus, marked elevation of the bile acids concentration, as well as a decreased concentration of glucose, cholesterol and TAG.

Faecal floatation revealed small numbers of oxyurid eggs. No parasites were observed in the floatation or in a direct faecal wet-mount.

A lateral radiograph revealed a marked soft-tissue opacity present in the region of the liver, with the border of the mass extending dorsally (Plate II, Fig. 3).

Magnetic resonance images showed a markedly enlarged left liver lobe distending and displacing the other abdominal organs. A mass attached to the left lobe extended ventromedially. This mass was about one third of the size of the left liver lobe. The gallbladder was not identifiable. The liver parenchyma was iso- to slightly hyperintense. The ventro-medial part of the left lobe showed a hypointense signal. This hypointense 
Table 1. Blood profile of the green iguana with hepatocellular carcinoma

\begin{tabular}{lclc}
\hline Value & \multicolumn{2}{c}{ Value } \\
\hline Total protein $(\mathrm{g} / \mathrm{l})$ & 51.4 & Haemoglobin $(\mathrm{g} / \mathrm{l})$ & 29.00 \\
Glucose $(\mathrm{mmol} / \mathrm{l})$ & 3.72 & PCV $(1 / 1)$ & 0.16 \\
ALP $(\mu \mathrm{kat} / \mathrm{l})$ & 1.55 & RBC $\left(10^{12} / \mathrm{l}\right)$ & 0.35 \\
ALT $(\mu \mathrm{kat} / \mathrm{l})$ & 1.03 & WBC $\left(10^{9} / \mathrm{l}\right)$ & 46.5 \\
AST $(\mu \mathrm{kat} / \mathrm{l})$ & 6.05 & Heterophils $\left(10^{9} / 1\right)$ & 23.25 \\
CPK $(\mu \mathrm{kat} / \mathrm{l})$ & 217.91 & Eosinophils $\left(10^{9} / 1\right)$ & 0 \\
Uric acid $(\mu \mathrm{mol} / \mathrm{l})$ & 321.58 & Basophils $\left(10^{9} / 1\right)$ & 0 \\
Triglycerides $(\mathrm{mmol} / \mathrm{l})$ & 0.09 & Monocytes $\left(10^{9} / 1\right)$ & 0 \\
Cholesterol $(\mathrm{mmol} / \mathrm{l})$ & 0.637 & Azurophils $\left(10^{9} / 1\right)$ & 23.25 \\
Bile acids $(\mu \mathrm{mol} / \mathrm{l})$ & 120.21 & Lymphocytes $\left(10^{9} / \mathrm{l}\right)$ & 0 \\
Calcium $(\mathrm{mmol} / \mathrm{l})$ & 2.32 & Calcium : Phosphorus & 0.57 \\
Phosphorus $(\mathrm{mmol} / \mathrm{l})$ & 4.04 & & \\
\hline
\end{tabular}

ALP - alkaline phosphatase, ALT - alanine aminotransferase, AST - aspartate aminotransferase

CPK - creatine phosphokinase, PCV - packed cell volume, RBC - red blood cells WBC - white blood cells

signal was not well demarcated from the left liver lobe. Free fluid signal surrounding the liver was seen. The stomach was empty and the caecum showed a heterogeneous signal intensity and was of a normal size. The small intestine and the colon were also a normal size with a hypointense signal. The pancreas and spleen were not possible to differentiate from the other abdominal organs. Both kidneys were found in a normal anatomical position and were of normal size. The urinary bladder was of medium size.

The findings in the liver were consistent with hepatic fibrosis/cirrhosis, diffuse neoplastic and/or inflammatory processes.

Endoscopy revealed a greatly enlarged pale liver and the presence of a straw-coloured effusion in the coelom. This fluid had the characteristics of a modified transudate with very low numbers of macrophages ( 1 cell in 8 fields examined microscopically at a magnification of $\times 200)$ and a low protein concentration $(30.2 \mathrm{~g} / \mathrm{l})$.

Necropsy revealed a greatly enlarged liver (Plate II, Fig. 4) with very hard consistency, splenomegaly and urinary bladder distension with urine. Histologically the liver showed an almost uniform proliferation of well differentiated duct and acinar tissue embedded in a large amount of connective tissue. In the tissues sampled for histology no normal liver tissue was present. The pathological findings were consistent with a non-cystic scirrhous hepatocellular carcinoma (Plate III, Fig. 5). The heart, lungs, kidneys, oesophagus, pancreas, spleen and stomach were without any microscopic changes. The caecum contained only residual parts of digested food.

\section{Discussion}

The MRI signal intensity of hepatocellular carcinoma varied (Hecht et al. 2006). Based on our MRI findings we were able to highly suspect liver pathology in this green iguana. It was however essential to obtain a liver biopsy for histopathological examination in order to confirm the diagnosis.

Hepatocellular carcinomas have been previously reported in a five-lined skink (Eumeces fasciatus) and an inland bearded dragon (Pogona vitticeps) (Griswold 2001). In a rattlesnake (Sistrurus catenatus) hepatocellular neoplasia involved much of the dark red and enlarged liver. Microscopically, these tumours consisted of proliferating large round to cuboidal cells arranged in loose trabeculae or cords. In some areas of the mass, there was evidence of bile duct proliferation, but these small ducts did not display features consistent 
with neoplasia (Hruban and Maschang 1982; Frye 1991). Our finding agrees with this description, but embedded in an increased fibrotic stroma.

A complete blood cell count in a bearded dragon suffering from hepatocellular carcinoma indicated heterophilia and lymphocytopenia (Griswold 2001). In the present case of hepatocellular carcinoma in a green iguana, heterophilia was associated with low numbers of erythrocytes, low haematocrit and a low concentration of haemoglobin. The anaemia can be attributed to insufficient liver function (Campbell 2004).

Persistent hyperglycaemia was present in a bearded dragon suffering from hepatocellular carcinoma (Griswold 2001) and hyperglycaemia was also detected in other lizard species (Iguana iguana and Physignathus cocincinus) with chronic renal failure, lipidosis of the liver or diabetes mellitus (Heatley et al. 2001; Crocker and Miller 2002). In the present study, the decrease in the glucose concentration in plasma was combined with high activities of AST and CPK, increased concentration of uric acid, phosphorus, and bile acids. While in the bearded dragon histopathological examination of the pancreas demonstrated nodular pancreatic hyperplasia (Griswold 2001), we did not observe any morphological changes of the pancreas in our iguana.

Studies that have been performed to characterize the bile acids in reptiles demonstrate that a variety of different bile acids are produced. They show that 3- $\alpha$ bile acids appear to be conserved amongst all reptile groups (Schaffner 1988; McBride et al. 2007; Knotková et al. 2008). Plasma $3 \alpha$-hydroxy-bile-acid reference intervals for healthy green iguanas have been published recently (McBride et al. 2007; Knotek et al. 2008). The mean plasma bile acid concentration in 110 samples of healthy green iguanas was $15.89 \pm 10.63 \mu \mathrm{mol} / \mathrm{l}$. In the present study the plasma bile acid concentration was significantly elevated. This result is in accordance with the results of our previous study (Knotek et al. 2008) focusing on green iguanas suffering from chronic liver disease.

\section{Acknowledgments}

This project received partial support from the Internal Grant Agency of the University of Veterinary and Pharmaceutical Sciences Brno (IGA Nr. 29/2007/FVL).

\section{References}

Aguirre DA, Behling CA, Alpert E, Hassanein TI, Sirlin CB 2006: Liver fibrosis: Non-invasive diagnosis with double contrast material-enhanced MR imaging. Radiology 239: 425-437

Bialecki ES, Di Bisceglie AM 2005: Diagnosis of hepatocellular carcinoma. J Int Hepato Pancreato Biliary Assoc 7: 26-34

Campbell TW 2004: Clinical chemistry of reptiles. In: Thrall MA (Ed.): Veterinary Hematology and Clinical Chemistry. Lippincott Williams and Wilkins, Baltimore, pp. 493-498

Clifford CA, Pretorius ES, Weisse C, Sorenmo KU, Drobatz KJ, Siegelman ES, Solomon JA 2004: Magnetic resonance imaging of focal splenic and hepatic lesions in the dog. J Vet Intern Med 18: 330-338

Crocker C, Miller D 2002: Persistent elevated blood glucose in the iguana, Iguana iguana: A case study. Proc. ARAV, Reno, pp. 7-9

Elsayes KM, Leyendecker JR, Menias CO, Oliveira EP, Narra VR, Chapman WC, Hassanien MH, Elsharkawy MS, Brown JJ 2007: MRI characterization of 124 CT-indeterminate focal hepatic lesions: evaluation of clinical utility. J Int Hepato Pancreato Biliary Assoc 9: 208-215

Frye FL 1991: Common pathologic lesions and disease processes: neoplasia. In: Frye FL (Ed.): Reptile Care. An atlas of diseases and treatments. T.H.F. Publications Inc., Neptune City, New Jersey, pp. 576-619

Griswold WG 2001: Hepatocellular carcinoma with associated hyperglycemia in an inland bearded dragon, Pogona vitticeps. Proc ARAV, Orlando, pp. 227-231

Gumpenberger M, Henniger W 2001: The use of computed tomography in avian and reptile medicine. Semin Avian Exotic Pet Med 10: $174-180$

Heatley JJ, Johnson A, Tully T, Mitchell M 2001: Persistent hyperglycemia in a chinese water dragon, Physignathus cocincinus. Proc ARAV, Orlando, pp. 207-211

Hecht EM, Holland AE, Israel GM, Hahn WY, Kim DC, West AAB, Babbs JS, Taouli B, Lee VS, Krinsky GA 2006: Hepatocellular carcinoma in the cirrhotic liver: Gadolinium-enhanced 3D T1 -weighted MR imaging as a stand-alone sequence for diagnosis. Radiology 239: 438-447

Hruban Z, Maschang ER 1982: Hepatocellular adenoma in a rattlesnake. J Comp Pathol 92: 429-435 
Knotek Z, Hauptman K, Knotková Z, Hájková P, Tichý F 2002: Haemogram and plasma biochemistry in green iguanas with renal disease. Acta Vet Brno 71: 333-340

Knotek Z, Mach V, Jekl V, Knotková Z 2007: MRI in diagnosis of swollen eyes syndrome in a green iguana. Proc Pathol Med Reptiles and Amphibians, Chimaira Frankfurt am Main, pp. 223-230

Knotek Z, Dorrestein GM, Knotková Z, Hrdá A 2008: Chronic liver failure in green iguanas. Proc BVZS Autumn Meeting, Stretton, pp. 45-47

Knotková Z, Dorrestein GM, Jekl V, Janoušková J, Knotek Z 2008: Fasting and postprandial serum bile acid concentrations in 10 of healthy female red-eared terrapins (Trachemys scripta elegans). Vet Rec 163: 510-514

Knotková Z, Pejřilová S, Trnková Š, Matoušková O, Knotek Z 2005: Influence of reproductive season upon plasma biochemistry values in green iguanas. Acta Vet Brno 74: 515-520

McBride M, Hernandez-Divers SJ, Koch T, Bush S, Latimer KS, Wilson H, Hernandez-Divers SM, Stedman NL 2007: Preliminary evaluation of pre- and post-prandial $3 \alpha$-hydroxy-bile-acids in the green iguana (Iguana iguana). J Herp Med Surg 16: 129-134

Oliva MR, Saini S 2004: Liver cancer imaging: role of CT, MRI, US and PET. Cancer Imaging 4: 42-46

Pejřilová S, Knotková Z, Knotek Z, Vrbas J 2004: Age-related changes of the haematological profile in green iguana (Iguana iguana rhinolopha). Acta Vet Brno 73: 305-312

Silverman S 2006: Diagnostic Imaging. In: Mader DR (Ed.) Reptile medicine and surgery. Saunders-Elsevier, St. Louis, pp. 471-489

Schaffner F 1998. The Liver. In: Gans C, Gaunt AS (Eds). Biology of the reptilia. Vol 19 (Morphology G). Society for Study Amphibians and Reptiles, Ithaca, New York, pp. 513-514

Szklaruk J, Bhosale P 2007: Hepatocellular carcinoma: MRI and CT examination. Israel Med Assoc J 9:153-155 
Plate I

Knotek Z. et al.: Hepatocellular ... pp. 243-247

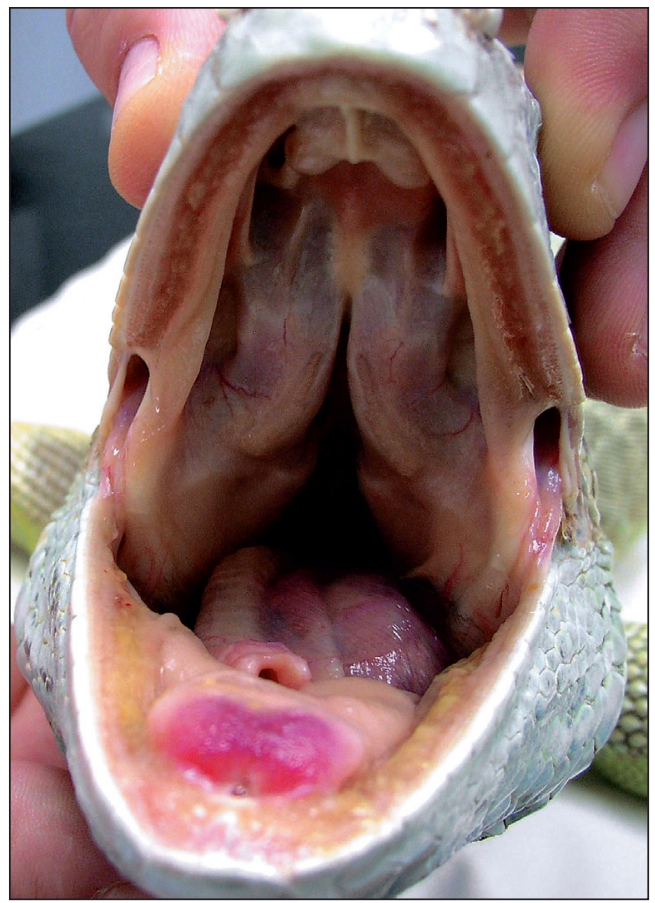

Fig. 1. Male green iguana with pale mucous membranes (ischaemia) of the oral cavity.

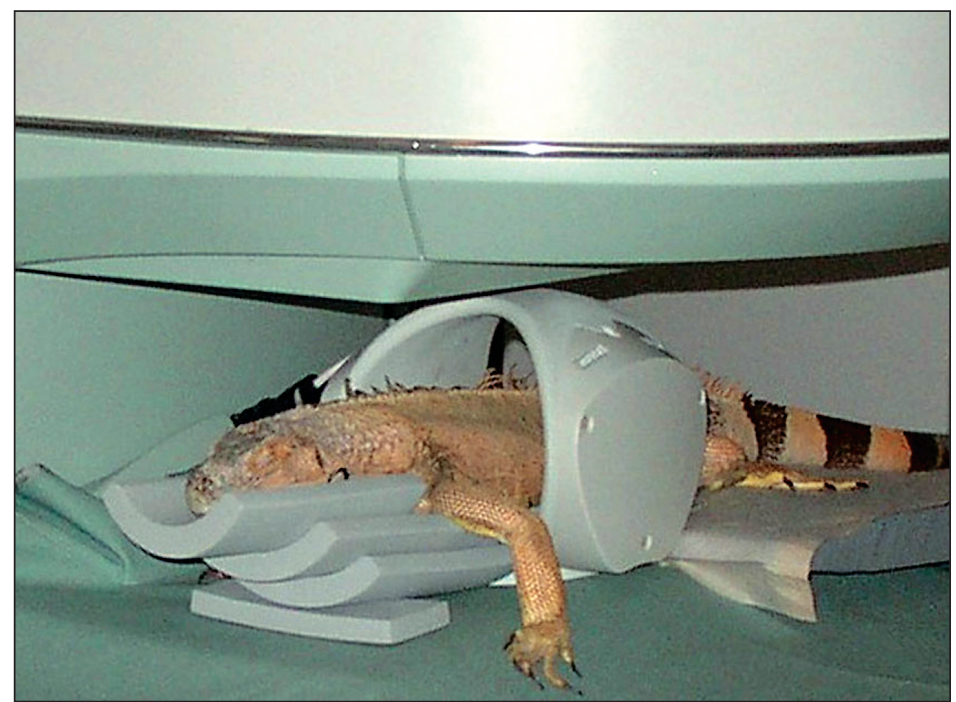

Fig. 2. Male green iguana ready for magnetic resonance imaging examination (sedated with tiletaminezolazepam). 


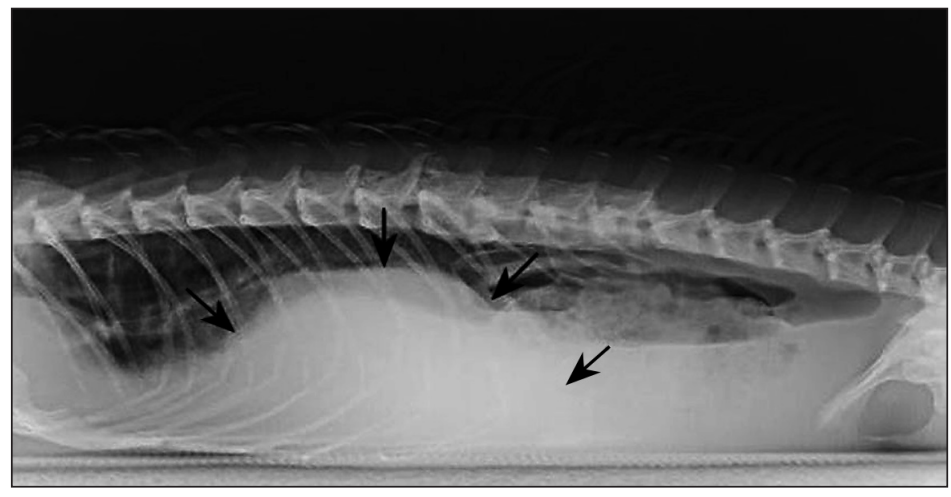

Fig. 3. Male green iguana - lateral radiographic study. Arrows: enlarged liver shadow.

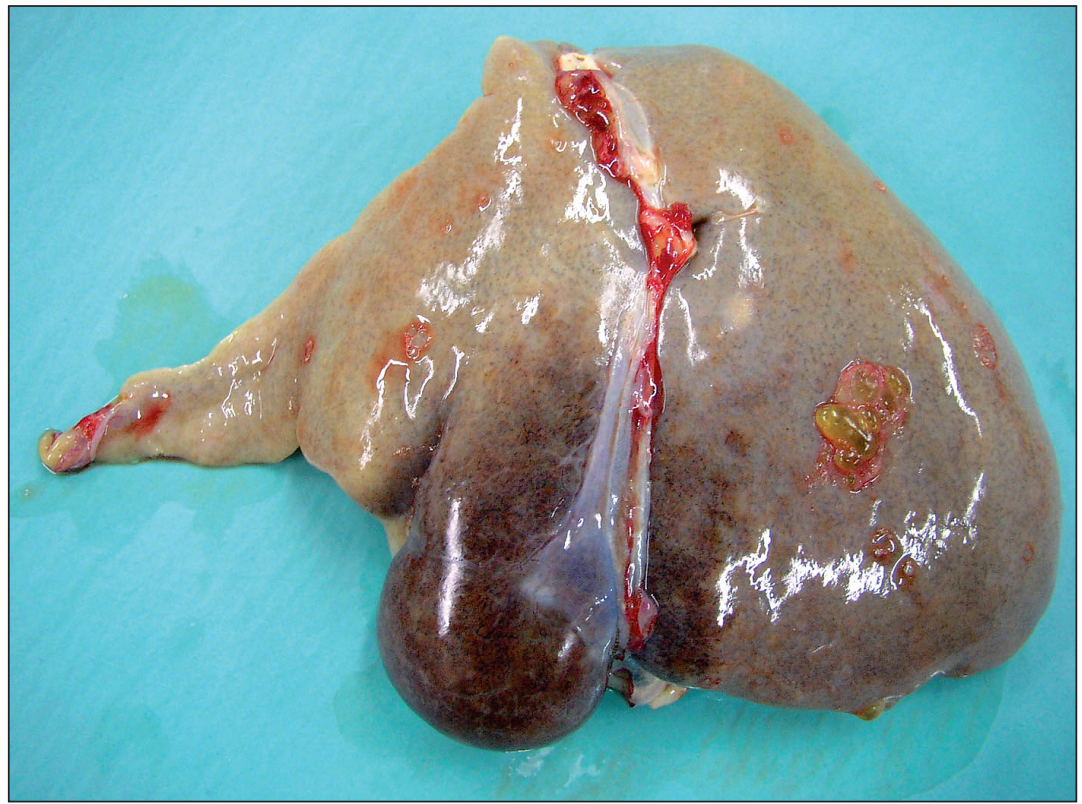

Fig. 4. Male green iguana - hepatomegaly. 
Plate III

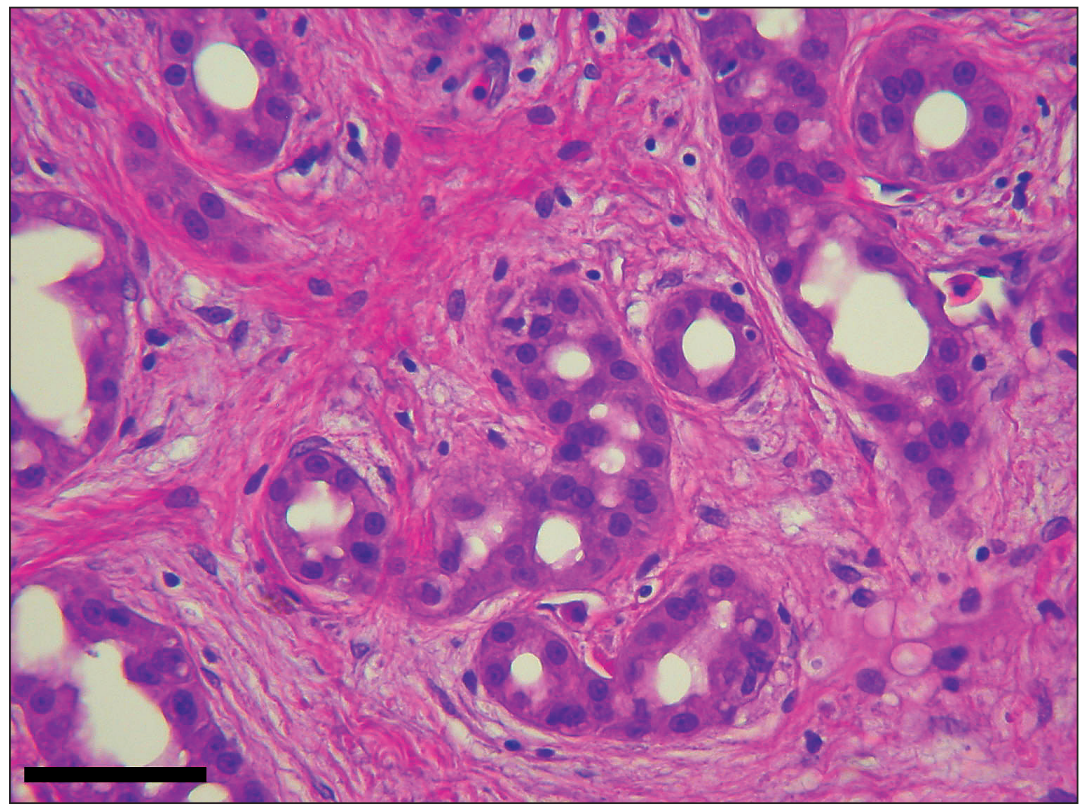

Fig. 5. Male green iguana - non-cystic scirrhous hepatocellular carcinoma. 